\title{
Reestruturação produtiva industrial e as consequências sociais e espaciais
}

Industrial productive restructuring and the social and spatial consequences

La reestructuración productiva industrial y las consecuencias sociales y

espaciales.

Restructuration de la production industrielle et conséquences sociales et spatiales

\section{Alexsandra M. Vieira Muniz}

\section{(2) OpenEdition}

\section{Journals}

\section{Edição electrónica}

URL: http://journals.openedition.org/espacoeconomia/9500

DOI: 10.4000/espacoeconomia.9500

ISSN: 2317-7837

\section{Editora}

Núcleo de Pesquisa Espaço \& Economia

\section{Refêrencia eletrónica}

Alexsandra M. Vieira Muniz, « Reestruturação produtiva industrial e as consequências sociais e espaciais », Espaço e Economia [Online], 16 | 2019, posto online no dia 03 janeiro 2020, consultado o 13 janeiro 2020. URL : http://journals.openedition.org/espacoeconomia/9500 ; DOI : 10.4000/ espacoeconomia.9500

Este documento foi criado de forma automática no dia 13 janeiro 2020.

(c) NUPEE 


\title{
Reestruturação produtiva industrial e as consequências sociais e espaciais
}

\author{
Industrial productive restructuring and the social and spatial consequences \\ La reestructuración productiva industrial y las consecuencias sociales y \\ espaciales. \\ Restructuration de la production industrielle et conséquences sociales et \\ spatiales
}

Alexsandra M. Vieira Muniz

\section{Introdução}

1 Considerando que a reestruturação produtiva ocasiona um reordenamento nas forças produtivas, nas relações de trabalho e, notadamente, no espaço, entendemos por reestruturação produtiva um viés da reestruturação maior do capitalismo que traz mudanças tanto de ordem técnico-econômicas quanto as socio institucionais que ocorrem em um determinado espaço.

2 Assim, não teriam sido possíveis as transformações em curso sem as mediações políticoinstitucionais, o potencial ideológico com um discurso racional que exerce papel fundamental no processo de acumulação do capital, as condições jurídico-políticas, ou seja, a base normativa pela intermediação do Estado e a mudança em sua forma de atuação.

3 No atual contexto, as arenas decisórias passam a ser outras, muitas delas fora dos limites do País, resultando, dentre outras coisas, na reestruturação da máquina Estatal.

O aparelho Estatal passa por verdadeira reestruturação, excluindo e instituindo órgãos indutores das novas exigências do capital e elaborando várias políticas públicas, que, no caso das voltadas ao setor industrial, são uma continuidade da política iniciada no País, por via da promoção da modernização, passando pelo período de integração produtiva 
nacional, marcado dentre outras coisas, pela intervenção planejada do Estado no Nordeste liderada pelo programa da Sudene (Superintendência do Desenvolvimento do Nordeste).

5 Já nos anos de 1990, sob um novo modelo de acumulação, ocorre maior liberalização da economia, cada vez mais marcada e dominada pela lógica do mercado em que predominam políticas do tipo federativas sujeitas às determinações globais, em virtude dos objetivos extrapolarem um planejamento no nível regional.

6 Trata-se de fato de um novo momento, em que a ordem competitiva constitui o principal argumento, já que, mesmo seguindo o mesmo objetivo do início das políticas de intervenção regionais, qual seja, a reprodução do capital, hoje, esta reprodução se dá de forma ampliada em escala global.

7 Neste cenário, o governo federal, objetivando dar continuidade às políticas de desenvolvimento, implementadas com a intervenção planejada do Estado a partir dos anos 1960, em particular na região nordeste em um contexto de redução das disparidades regionais diante do destaque do sudeste industrial, somente após os anos de 1980 ao mesmo tempo em que reduzia os gastos públicos, passou a maximizar a oferta de fatores locacionais, capazes de atrair os investimentos privados.

8 É, então, sob um novo contexto que o Estado passa a ser agente facilitador da reestruturação capitalista portadora de novas formas de produção e de trabalho.

9 Diante disto, percebemos o Estado assumindo o papel de locomotiva das transformações por intermédio de seu aparato institucional, incorporando diversos setores na economia de mercado, adaptando a organização social, espacial e econômica às novas necessidades do capital e assim organizando um espaço apto ao desenvolvimento da atividade capitalista. Isto é evidente tanto analisando uma escala maior, como em particular é o que vemos acontecer nas Regiões Metropolitanas com a difusão da produção industrial para municípios além da capital.

No Ceará, a indústria têxtil, em particular, se concentra na capital com tendência a maior dispersão de indústrias de grande porte na RMF, com presença também do capital industrial do sudeste e sul do país com suas filiais e algumas vezes com a transferência da matriz. De um total de 635 indústrias têxteis no Estado do Ceará, 399 estão na RMF, sendo que deste total 72\% (286) das indústrias têxteis se concentram na Capital (MUNIZ, 2014).

11 O Estado mantém-se na dianteira da criação das condições necessárias à reprodução ampliada do capital. Então, podemos perceber que o Estado está cada vez mais intervindo na estrutura produtiva, ditando as regras do jogo e arcando com parte dos custos de produção.

12 O motor do crescimento passa a ser a integração com a economia internacional, que, ante a transferência dos níveis supranacional, para o nacional, regional ou local do exercício de regulação, o Estado, representado por diversas instituições, exerce o papel de intermediário na adequação da produção e do espaço às exigências dos agentes financeiros internacionais, constituindo o espaço do capital.

Desta forma, dentre as múltiplas expressões da reestruturação capitalista, temos a readaptação do Estado às mudanças que o sistema capitalista à escala planetária está exigindo, passando a ser um componente estratégico ao criar as condições para que as ações se concretizem, adequando a produção e o espaço a um processo de regulação comandado pelo mercado global. 
14 Assim, a abertura à competição global, somada à intensificação das práticas neoliberais em um ambiente de reestruturação produtiva, trouxe consigo um conjunto de transformações.

15 À despeito do destaque do setor de serviços, ações são direcionadas para o fortalecimento da indústria, visando à implantação, realocação, ampliação, recuperação e reestruturação de indústrias. Para isto, ocorre a ampliação da infraestrutura, do aparato científico-tecnológico, dos cursos de capacitação, das escolas profissionalizantes e dos cursos das universidades públicas e privadas.

16 No Ceará, destacam-se as políticas de incentivo à industrialização via Fundo de Desenvolvimento Industrial (FDI), mediante isenção e prorrogação de incentivos fiscais, redução de impostos para indústrias que venham a se instalar na Capital, Região Metropolitana ou restante do Estado.

17 Diante deste cenário maior da dinâmica atual que perpassa o papel do Estado, bem como a política industrial, buscamos vislumbrar no Tópico 2 : Reestruturação Produtiva e Espacial: Do Conceito e Contexto às Consequências na Atividade Industrial, o conceito de reestruturação, sua caracterização no setor industrial, sua periodização ao longo do desenvolvimento do capitalismo e alguns reflexos na atividade industrial, na sequencia temos as Considerações Finais.

\section{Reestruturação Produtiva e Espacial: do conceito e contexto às consequências na atividade industrial}

18 Antes de tecer algumas considerações acerca da reestruturação industrial, faz-se mister explicitar o conceito de reestruturação que para Soja (1993, p.193)

[...] em seu sentido mais amplo, transmite a noção de uma 'freada', senão de uma ruptura nas tendências seculares, e de uma mudança em direção a uma ordem e uma configuração significativamente diferentes da vida social, econômica e política. Evoca, pois, uma combinação sequencial de desmoronamento e reconstrução, de desconstrução e tentativa de reconstituição, proveniente de algumas deficiências ou perturbações nos sistemas de pensamento e ação aceitos. A antiga ordem então suficientemente esgarçada para impedir os remendos adaptativos convencionais e exigir, em vez deles, uma expressiva mudança estrutural.

19 Nesta mesma linha de análise, coadunamos com Lencioni (1998b), ao afirmar que a reestruturação é algo em movimento e não estático até o momento da ruptura, como se fosse uma nova estrutura que se sobrepõe à anterior.

Gomes (2011) traz o debate sobre a reestruturação produtiva à luz do arcabouço teórico já desenvolvido por estudiosos de áreas diversas do conhecimento.

21 É no setor industrial onde a reestruturação ocorre de modo mais intenso, dentre outras coisas, por via dos novos padrões da gestão/organização do trabalho, que assume importância decisiva na flexibilização das relações de trabalho com impactos socioeconômicos e espaciais.

22 Partindo do pressuposto que a reestruturação produtiva ocasiona um reordenamento nas forças produtivas, nas relações de trabalho e, notadamente, no espaço, entendemos por reestruturação produtiva tanto as mudanças de ordem técnico-econômicas quanto as socio institucionais que ocorrem em um determinado espaço, como afirmamos anteriormente. Daí concordarmos com Gottdiener (1993), que afirma ser a reestruturação um fenômeno socioespacial. 

bases fundadas no modelo desenvolvimentista adotado com ênfase na industrialização, por ter inspirado diretamente as políticas implementadas no País desde a década de 1950.

Alves (2000), analisando a reestruturação produtiva no setor industrial brasileiro, divide-a em três fases:

A primeira ocorre após 1945, quando surge o primeiro surto de reestruturação produtiva no Brasil, vinculado à instauração da grande indústria de perfil taylorista-fordista. Ele se desenvolve a partir de meados dos anos 50, no governo Kubitschek, representando a época do desenvolvimentismo. Depois, o segundo surto de reestruturação produtiva ocorre na época do 'milagre brasileiro', na ditadura militar, na passagem para os anos 70. Na verdade, ele é decorrência dos impulsos da industrialização, constituídos em meados da década de 1950. Finalmente, o terceiro - e atual - surto de reestruturação produtiva vinculasse à época da crise do capitalismo brasileiro, com o predomínio de um novo padrão de acumulação capitalista - a acumulação flexível - cujo 'momento predominante' é o toyotismo. Ele ocorre a partir dos anos 80, impulsionando-se na década seguinte os anos 90, sob a era neoliberal. É o que Alves denomina complexo de reestruturação produtiva (ALVES, 2000, p.103).

O atual processo de reestruturação produtiva é denominado, por Alves, de complexo de reestruturação produtiva por considerá-la

[...]uma ofensiva do capital na produção, que busca constituir um novo patamar de acumulação capitalista em escala planetária e tende a debilitar o mundo do trabalho, promovendo alterações importantes na forma de ser (e subjetividade) da classe dos trabalhadores assalariados (IBIDEM., p.11).

Em linhas gerais, a reestruturação, calcada na produção flexível, propiciou uma reorganização do processo da gestão da produção e da força de trabalho, com outras práticas gerenciais, uma nova lógica de produção de mercadorias, o desenvolvimento de novas tecnologias e a descentralização produtiva, com a terceirização ou as relocalizações industriais. Isto ocasionou o fechamento de indústrias e abertura de outras; a modificação das regras institucionais de relacionamento entre capital e trabalho; as mudanças de hábito no consumo; as alterações nos padrões de concorrência intercapitalista etc.

Com a reestruturação, modificam-se as condições técnicas, jurídico-políticas e sociais, as formas de organização do trabalho e do processo de produção, com introdução de novas práticas gerenciais. Isso implicou também transformações nas relações entre capital e trabalho, com a instauração de novas legislações trabalhistas de cunho flexível, adaptando-as às necessidades do capital.

Dentre outras evidências do atual período, temos, ainda, o crescimento do mercado de mão de obra feminina e do setor de serviços, a subcontratação que permite ao empregador custo inferior ao de um trabalhador regular e o estabelecimento de vínculos empregatícios com outras empresas - geralmente as empresas maiores transferem responsabilidades e riscos para as menores (DRUCK, 1995).

Em nome da competitividade e majoração da taxa de lucros, o que presenciamos é a flexibilização das leis trabalhistas, um dos pilares do atual modelo produtivo, o que em outros termos significa excluir uma crescente massa de trabalhadores do gozo de seus direitos legais, resultado de conquistas históricas contidas na legislação trabalhista, cuja existência passa a ser denunciada como obstáculo à expansão do emprego formal 
(ANTUNES, 1997). Conforme relata Edwards, apud Singer (1998, p.113), "aquilo que por um lado foram conquistas da organização dos trabalhadores acabaram, por outro, tornando-se restrições crescentes ao ajuste do mercado de trabalho".

A terceirização também é cada vez mais frequente. Para Druck (1995), a intensificação do ritmo das terceirizações no Brasil, desde os anos 1990, está intimamente ligada à inserção do modelo japonês nas empresas brasileiras, o que ocorreu inicialmente no setor automobilístico.

Observam-se, juntamente com as inovações tecnológicas, a introdução de procedimentos organizacionais globais $\left(k_{a b a n}{ }^{1} \text {, just in time }\right)^{2}$; uma série de racionalizações da produção (downsizing ${ }^{3}$ e a reengenharia), melhor controle da qualidade do produto e maior produtividade com a introdução de programas de qualidade total que possibilitam o gerenciamento do trabalho via círculos de controle de qualidade e gestão participativa que permitem uma maior economia de espaço, tempo de produção, maior controle de qualidade do produto e, consequentemente, maior produtividade.

Com a disputa por novos mercados e a competição em escala global, que passam a exigir do setor produtivo a adoção de medidas criativas e restauradoras de sua capacidade produtiva e competitiva, além de estimular os investimentos para a criação de novos produtos, o trabalho, assim como a sociedade, se veem perpassados por uma intensa e progressiva racionalização que se assenta na reestruturação das técnicas produtivas e gerenciais.

Padrões tecnológicos anteriormente considerados estáveis sucumbem aos imperativos da competição global, dada a ênfase em novos produtos e novas tecnologias, justificados pela busca desenfreada de novas formas de obtenção de lucro, fazendo com que o que hoje é considerado novo no mercado venha a ser mais um novo-velho produto, suplantado pela força da destruição criativa das inovações.

Essa lógica reativa e inovativa do capital para enfrentar a crise é denominada de destruição criativa ${ }^{4}$ uma produção fugidia e efêmera, em que as indústrias, na busca de novos mercados, alteram, no todo ou em parte, as características do seu produto, e assim reduzem a sua vida útil, é o que chamamos hoje de obsolescência programada.

A rapidez das inovações impelidas por uma competição cada vez mais acirrada em um mercado mundial, no entanto revela a capacidade para enfrentar a força da destruição criativa das inovações, que, por sua vez, é inerente ao sistema capitalista.

A busca pelo aumento da produtividade e o restabelecimento espacial das estruturas de acumulação, que foram os mesmos objetivos da Revolução Industrial, são também o que impulsiona, em um quadro mundial de concorrência capitalista, as unidades produtivas a executarem modificações nos processos de trabalho, acelerando a inserção de inovações tecnológicas na produção.

Ocorrem inovações tecnológicas na produção, cuja expressão é a nanoeletrônica, "a microeletrônica, a automação, a robótica, a informática e as redes que aceleram e multiplicam a capacidade produtiva da força de trabalho". (IANNI, 1997, p.157).

Pari Passu às inovações, são implementadas novas políticas de gestão da produção e de organização do trabalho, um conjunto de técnicas que se alastrou pelos países capitalistas centrais e periféricos, reestruturando o processo produtivo dos diversos setores econômicos, com o escopo de propiciar elevado patamar de qualidade e competitividade. 

grandes avanços científico-tecnológicos e a espetacular expansão das redes de comunicação e transporte foram condição sine qua non para a reestruturação produtiva e espacial em curso, uma vez que permitiu a dispersão mundial da produção e a criação de "espaços inteligentes", onde a lógica capitalista possa fluir. Em outras palavras, está havendo, uma transnacionalização que alcança espaços até agora não penetrados pelo capital (SANTOS, 1996).

41 A economia de tempo, articulando Geografia e História, nos faz perder a noção de tempo e de espaço, o que nos leva a falar na compressão do espaço-tempo (HARVEY, 1993), em que o ciberespaço é a expressão tangível. Como nos dizia Santos:

[...] com a evolução dos sistemas de engenharia, a própria noção de tempo muda: o tempo da produção, o tempo da circulação, o do consumo e da realização da maisvalia. Quanto mais evoluem os sistemas de engenharia, mais coisas se produzem em menos tempo. Também se transportam mais objetos em menos tempo, o consumo se faz mais imediatamente, tornando tudo isso mais e mais fácil [...] (SANTOS, 1988).

No atual contexto de reordenação da produção, circulação e consumo, presenciamos a livre movimentação de mercadorias e de capitais por via das fronteiras, atravessando as mais diversas formas de organização social do trabalho e produção, além da ampliação da concorrência entre os países e o "encurtamento de distâncias", permitindo a integração e a regulação final do processo de produção global.

Há cada vez menos barreiras para a circulação do fator capital - em linhas gerais o mesmo se aplica às mercadorias -, no entanto, há crescentes barreiras dificultando a circulação do fator trabalho, pelo menos dos trabalhadores de baixa qualificação. (SENE, 2004, p.69).

Não há como negar que as transformações em curso se manifestam ao nível da divisão do trabalho, uma vez que "a desconcentração geográfica da cadeia produtiva acarreta uma extensão da divisão social do trabalho" que, por sua vez, permite "a reorganização da produção e a emergência de um novo modelo de organização territorial”. (BENKO, 1999).

Com efeito, em função de maior capacidade de acumulação resultante da redefinição de estratégias de mobilidade espacial do capital, em termos de sua reprodução global, verificamos uma reorganização da divisão espacial do trabalho.

Dessa forma, "uma nova divisão social e territorial do trabalho é posta em ação, envolvendo introdução e difusão de novas tecnologias e outras relações espaciais", ou seja, "as relações econômicas e sociais são ampliadas, passando a se realizar em amplos territórios e a articulação entre as diversas unidades territoriais especializadas é viabilizada pelo progresso dos meios de comunicação", quando então o mundo do trabalho passa a ocupar uma escala anteriormente desconhecida (CORRÊA, 1995).

No Brasil, somente na segunda metade dos anos 1980, evidenciam-se timidamente um novo paradigma tecnológico e produtivo e uma nova organização do trabalho e do espaço. Benko (1999) ressalta que, "desde os anos 80 - observam-se os primeiros sinais do advento de novo período de desenvolvimento do capitalismo".

Espaço e Economia, 16 | 2019 

qual esta

[...]na medida em que ainda é uma forma própria do capitalismo, mantém três características essenciais desse modo de produção. Primeira: é voltado para o crescimento; segunda: este crescimento em valores reais se apoia na exploração do trabalho vivo no universo da produção e, terceira: o capitalismo tem uma intrínseca dinâmica tecnológica e organizacional.

51 A periodização da atual fase da reestruturação e sua relação intrínseca com o desenvolvimento do capitalismo se fazem necessárias, uma vez que a reestruturação produtiva atual está relacionada com a crise do modelo de produção até então vigente. Portanto, cabe aqui fazer breve resgate deste contexto. dos anos 1970, não mais se sustentavam. Neste percurso, as transformações do modo de produção capitalista representam uma reação dos capitalistas à crise do modo de acumulação fordista, inaugurada pela fase $\mathrm{B}$ do $4^{\circ}$ ciclo de Kondratieff ${ }^{6}$, e, por conseguinte, a continuidade do processo de acumulação em seu movimento cíclico. "O capitalismo tende, ativamente, a produzir algumas das barreiras para o seu próprio desenvolvimento. Isso significa que as crises são endêmicas ao processo capitalista de acumulação" (HARVEY, 2005, p. 45).

Apesar da busca permanente para libertar os processos produtivos/comerciais/ financeiros de todas as formas de rigidez próprias do fordismo, o novo paradigma tecnológico/organizacional cuja característica essencial pode ser resumida em uma palavra, qual seja: flexibilidade(HARVEY, 1993), não consegue se consolidar como padrão sólido e universal, estando o desemprego, a inflação, a recessão e as dívidas públicas a revelarem a fragilidade da nova forma de acumulação capitalista.

Neste contexto, a reestruturação produtiva acelerou-se rapidamente desde os anos 1990, quando ocorreu a abertura da economia. Alves (2001) afirma ser este momento uma nova etapa do desenvolvimento do capitalismo caracterizada pela predominância do capital financeiro no processo de acumulação capitalista, ou seja, mercado de 
dinheiro e de crédito sem Estado, denominada por Santos (1994) creditização do território e por Chesnais (1999) de regime de acumulação financeirizada mundial.

Com o modo de acumulação sob a dominância do capital financeiro denominado de mundialização do capital (CHESNAIS, 1996), uma denominação mais precisa para o fenômeno da globalização $0^{7}$ em nossos dias, a ciência e a tecnologia a serviço direto da produção e reprodução do capital invadem os setores produtivos com muito mais ímpeto, transformando as relações de trabalho, criando um novo ethos para estas relações, uma nova via de racionalização do trabalho adequadas às novas necessidades de acumulação do capital "enquanto sujeito da modernidade exacerbada(ou da pósmodernidade)"(ALVES, 1999, p.22). Segundo Santos (2000, p. 23), "nos encontramos em um novo patamar da internacionalização, com uma verdadeira mundialização do produto, do dinheiro, do crédito, da dívida, do consumo, da informação".

Nesse contexto, a mundialização do capital (SANTOS, 2000) tendeu a impulsionar o processo de reestruturação, ao determinar, pela disputa por novos mercados e competição em escala global, transformações no espaço e na estrutura produtiva, difundindo a modernização dos processos de trabalho e produção de forma a intensificar a produtividade. A mundialização permitiu o aprofundamento do processo de reestruturação, resultando na reterritorialização ou recuperação político-territorial do poder de trocas globais para obtenção de vantagens competitivas entre as nações.

59 A reestruturação produtiva assentada na divisão do trabalho entre unidades produtivas integradas espacialmente articula-se, portanto, às duas faces da mesma moeda - uma diz respeito à crise do capitalismo, tendo sido uma resposta ao esgotamento do padrão de crescimento econômico capitalista até então vigente, e, por conseguinte, da redução da taxa de lucro e a outra à mundialização do capital, uma vez que, para adequar a economia ao mercado global, havia necessidade de se reestruturar o modo pelo qual se organizavam a produção,

60 Segundo Santos (2000, p.23), "nos encontramos em um novo patamar da internacionalização, com uma verdadeira mundialização do produto, do dinheiro, do crédito, da dívida, do consumo, da informação".

61 Mesmo sabendo que os impactos da reestruturação na indústria difere segundo o tipo de indústria, produção e alcance da produção, o espaço onde a indústria se instalou, o porte da indústria etc., algumas características do processo em curso já são notáveis, algumas das quais se repetem nos variados ramos industriais, outras possuem especificidades de alguns tipos de indústrias.

62 Considerando que as transformações no setor industrial se delinearam segundo os objetivos e diretrizes da política industrial, cabe destacar o fato de que,

As primeiras indicações dos objetivos e diretrizes da nova política industrial foram explicitadas na Exposição de Motivos da Medida Provisória 158, publicada em 15 de março de 1990. As bases da nova política estavam enfocadas na questão da competitividade, em contraponto às políticas adotadas anteriormente, que objetivavam a expansão da capacidade produtiva mediante o incentivo à substituição das importações. (REGO E MARQUES, 2006, p.212).

63 Para Rego e Marques (2006, p.213), em meados de 1990, esta proposta inicial foi detalhada nas Diretrizes Gerais para a Política Industrial e de Comércio Exterior (PICE). O objetivo central da nova política industrial era o aumento da eficiência na produção e comercialização de bens e serviços, com base na modernização e reestruturação da 
indústria. Para isto foram criados o Programa de Competitividade Industrial (PCI) e o Programa Brasileiro de Qualidade e Produtividade (PBQP).

Centrada principalmente na adoção de novas formas de gestão/organização da produção, a reestruturação industrial se aprofundou com a política de estabilização implementada com o Plano Real, no governo Cardoso, em 1994, com a subvalorização do dólar perante o real e uma grande facilidade para importação, que exigiu das indústrias transformações em ritmo acelerado e associações com capitais estrangeiros, para poderem sobreviver.

Esta forma de atuação do Estado brasileiro teve grande impacto na economia nacional e em particular no setor industrial, que passou por significativas mudanças associadas à implantação de indústrias atraídas por incentivos estaduais e regionais, à modernização dos equipamentos, além da introdução de técnicas mais modernas de organização e gerenciamento da produção.

Os impactos da reestruturação produtiva na indústria, se traduzem no dualismo do mercado de trabalho, dado o desemprego crescente acompanhado do aumento do emprego formal, em novos requisitos e qualificações da força de trabalho com o surgimento de postos de trabalho, ocasionando assim modificações na estrutura profissional e na equação dos empregos, na intensa mobilidade da força de trabalho, no crescente emprego da mão de obra feminina e juvenil, na intensa divisão e degradação do trabalho, cada vez mais desqualificado, e, para os que são contratados, na expansão do espírito capitalista (individualismo), na insegurança dada a ameaça constante do desemprego, na intensificação da jornada de trabalho, paralelamente, vem ganhando espaço as terceirizações, a presença de estagiários, as péssimas condições de trabalho, o aviltamento das relações de trabalho, o que significa criar as condições propícias para o aumento da exploração do trabalho, na redução dos índices de sindicalização etc.

Assim, podemos destacar dentre as consequências trazidas pelo processo de reestruturação:

- Crescente racionalização do processo de trabalho;

- Redução do tempo de produção;

- Aumento da produtividade do trabalho;

- Aumento do desemprego para os trabalhadores de baixo nível técnico e educacional;

- Intensa exploração (direta e indireta) da força de trabalho;

- Aumento da intensidade e do ritmo da jornada de trabalho;

- Demanda por força de trabalho não qualificada ou semiqualificada em determinados ramos produtivos;

- Ampliação da divisão social e espacial do trabalho;

- Maior inserção das mulheres, jovens e de trabalhadores das faixas etárias mais elevadas no mercado de trabalho;

77 - Dualismo do mercado de trabalho (maior "qualificação", escolarização e maiores salários \& empregos instáveis - precários, temporários, “desqualificados” e com salários inferiores);

78 • Cooperação, trabalho em equipe, polivalência e multifuncionalidade;

79 - Maior mobilidade da força de trabalho;

80 - Crescimento da terceirização; 
81 - Inadequadas condições de trabalho (segurança, higiene e saúde no trabalho);

- À divisão social do trabalho fundamentada nas diferenças de sexo, idade e na força física soma-se a busca pela redução da hierarquia entre o trabalho intelectual e o trabalho manual, eliminação dos escalões de comando intermediários, especificamente nos pontos de contato com a produção; pesquisa e desenvolvimento como destaca Manzagol (1985), cuja expressão maior é a presença dos "tecnopolos", parques empresariais e científicos especializados no desenvolvimento de tecnologia de ponta. As regiões de Campinas (favorecida pela presença da Unicamp), de São José dos Campos (onde está localizado o Instituto Tecnológico da Aeronáutica - ITA) e São Carlos (que abriga a UFSCar e um campus da USP) são alguns dos centros industriais que ostentam as tecnologias mais avançadas do País e expressam bem a crescente associação entre ensino, pesquisa e indústria. exemplo, na indústria têxtil, a etapa de fiação dinamizada pelos filatórios open-end e as tecelagens incrementadas com teares a ar comprimido. É certo que o uso das maquinarias é muito mais veloz e implementadas visando a qualidade do produto.

Por outro lado, além das transformações na estrutura organizacional das indústrias, os processos de reestruturação, movidos pela incorporação de tecnologia, contribuíram para aumentar o nível de desemprego, sendo esta uma de suas consequências sociais. É o que constata Lencioni, ao fazer uma radiografia da dinâmica do emprego industrial na indústria de transformação

Com o processo de reestruturação produtiva que assolou o mundo e trouxe profundas modificações no parque industrial brasileiro, houve uma perda significativa do emprego industrial. Para se ter uma idéia dessa perda, vale lembrar que nos anos de 1970 o emprego industrial significava 20\% dos empregos do país, tendo passado, nos anos de 1990, para 13\%. E essa perda ganha mais expressão quando vemos que entre 1980 e 1990 foram eliminados um milhão e meio de postos de trabalho na indústria. 
[...] a cidade de São Paulo, passou por um processo bastante acentuado de perda do emprego industrial, muito embora seja ainda e, de longe, a maior cidade industrial do País. (LENCIONI, 2006, p.107-109).
Sudeste do País, em parte em razão da dispersão espacial de indústrias em busca de redução de custos de produção, Lencioni, ao dissertar acerca do rearranjo na distribuição territorial da indústria, enfatiza que esta continua muito concentrada no Sudeste, particularmente no Estado de São Paulo e diz que
A reestruturação produtiva significou, portanto, uma desconcentração da indústria de São Paulo e da região metropolitana para o interior paulista; mas significou, também, uma dispersão territorial da indústria para outros estados. Isso não quer dizer que houve uma transferência de plantas industriais localizadas na cidade de São Paulo; essa relocalização, pode ter até ocorrido, mas sobretudo o que houve foi a eleição de novas localizações para a instalação de novas industriais. (LENCIONI, 2006, p. 109)

Partindo do pressuposto de que a dispersão industrial que ocorreu na década de 1970 foi motivada pelos desequilíbrios regionais que levaram o governo a adotar medidas, como incentivos fiscais e programas para as áreas periféricas, é importante ressaltar que, na década de 1990, a "nova desconcentração" ganhou o nome de "Guerra Fiscal" ou "Guerra dos Lugares" (SANTOS E SILVEIRA, 2001), entre os Estados, pois as indústrias são disputadas entre os Estados, que oferecem terrenos e isenções. Conforme Lencioni (2006), as indústrias que, por exemplo, deixam o Estado de São Paulo alegam que o processo de globalização exige custos finais mais baixos para ganhar competitividade, aproveitando a mão de obra mais barata e menos politizada. Desta forma, na década de 1990, a distribuição espacial da indústria passou a receber transformações significativas. Nas regiões de concentração tradicional, como a grande São Paulo, muitas indústrias se deslocaram em virtude da deseconomia de aglomeração, ou seja, os congestionamentos de trânsito, o alto preço dos terrenos, a elevada carga de impostos e a mão de obra mais cara e sindicalizada, que inibem os novos investimentos.

Esse cenário é novo e, embora muito dele se deva à mobilidade territorial das indústrias que operam com força de trabalho intensiva, não se confunde com a mobilidade territorial das indústrias havida em décadas anteriores ao processo de reestruturação produtiva. Não se confunde porque embora seja, igualmente, um processo de mudança de localização territorial, ele é de outra natureza. Àquele, o anterior, se relaciona a uma fase do processo de industrialização brasileira que se desenvolveu baseada numa política de substituição de importações, de protecionismo alfandegário e de uso intensivo dos fundos públicos. Esse outro, que acompanha a reestruturação produtiva, se relaciona às políticas neoliberais e ao incremento de uma arquitetura produtiva estruturada em torno de empresas organizadas em redes e em empresas-rede. (LENCIONI, 2006, p. 108-109). 
Como nos fala Lencioni, os dados apontam.

Conforme Santos e Silveira (2001:108) "a nova divisão do trabalho industrial é acompanhada de uma nova repartição geográfica". O autor mostra a geografia da indústria nacional e, por conseguinte, a nova diferenciação regional que se delineia com base nos tipos de indústria que se instalam nas diferentes regiões do Brasil.

Esse cenário indica que uma nova diferenciação regional, que é produto não mais da simples presença, densidade ou ausência da atividade industrial nas diferentes regiões do País, mas, sobretudo, do tipo de indústria que se instala nas diferentes regiões do País. (LENCIONI, 2006, p.108).

A dispersão geográfica da produção industrial estendendo-se para novos espaços do Sul e alguns espaços do Centro-Oeste e Norte do Brasil, bem como do Nordeste, em decorrência da descentralização industrial (SANTOS e SILVEIRA, 2001), ou melhor, desconcentração industrial (LENCIONI, 1991, 2006, 2007), é uma evidência no território

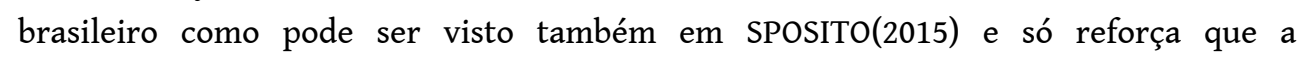
reestruturação é um "fenômeno socioespacial" Gottdiener (1993, p.230).

20 atual processo de reestruturação industrial propicia mudanças nos equipamentos e nos fluxos urbanos, resultando em novas formas de apreensão espacial, uma vez que o surgimento ou relocalização industrial impulsiona muitas vezes o processo de metropolização além de induzir a reinvenção de espaços urbanos, revelando a recriação da cidade do/para o capital.

Com a reestruturação em curso, se acentua as relações comerciais e a distribuição da produção em espaços cada vez mais longínquos. A antiga rede urbana cede lugar aos circuitos espaciais da produção global em que as indústrias mantêm pouca relação com o espaço próximo no que se refere à distribuição da produção ou importação de matéria-prima, porém no que diz respeito ao processo produtivo no chão de fábrica e as transformações no espaço urbano do entorno onde se implantam, as interações com o espaço local são mais perceptíveis, seja no que diz respeito ao impulso no setor de serviços ou fixos espaciais ligados à reprodução da força de trabalho com instituições de ensino técnico e tecnológico, além dos espaços de reprodução do trabalhador com o serviço de habitação ou as antigas vilas operárias, sem esquecer o recrutamento de trabalhadores próximo ao estabelecimento industrial, pois mesmo em função do desemprego estrutural, a própria característica de determinados ramos industriais, como o têxtil, de calçados e alimentos requer a utilização de considerável mão de obra.

4 Enfim, é um processo plural, heterogêneo, que demanda estudos de caso que venham refutar ou não algumas afirmações, como também elucidar, confirmar ou negar o que

\section{Considerações Finais}

5 A análise das transformações atuais do setor industrial no contexto da reestruturação produtiva exigiu a compreensão, mesmo que sucinta, de sua relação com o contexto maior da reestruturação capitalista, já que os impactos na esfera produtiva e espacial é uma das múltiplas facetas deste processo.

Os fatos até aqui expostos corroboram para afirmar que a adoção de uma política de abertura do capital à competição global e a busca de uma integração mais estreita à economia mundial, somada à intensificação das práticas neoliberais em um ambiente de 
reestruturação produtiva, trazem consigo um conjunto de transformações que imprimem marcas profundas em todas as esferas da sociedade.

107 A tentativa de manter o crescimento de décadas anteriores mediante participação mais ativa do Governo Estadual e a parceria com o Governo Federal, sendo os principais instrumentos da atual política industrial a atração de investimentos externos com a concessão de incentivos fiscais/financeiros e de infraestrutura, aproveitando também a vantagem da mão de obra barata, enseja diversos questionamentos, como o desafio das indústrias já existentes e despreparadas para enfrentar a concorrência desigual e a possibilidade de reduzir a capacidade de poupança do Governo com o reforço às isenções e incentivos fiscais, dando maiores condições à vinda de empresas externas e de maior poder de barganha.

Mesmo não sendo possível evidenciar de forma mais aprofundada as particularidades inerentes ao desenvolvimento do capital industrial em seus diferentes ramos devido aos limites a serem seguidos na construção do presente artigo, sabemos que a caracterização geral deste fenômeno em estudo se delineia e se manifesta em sua pluralidade .

Para além das transformações gerais na indústria sabemos que a função industrial não é mais dominante no espaço urbano e nas economias de grandes metrópoles globais, muitas cidades, não se firmam mais como cidade industrial, mas avançam como cidade do terciário, em razão do crescimento do comércio e dos serviços, das atividades ligadas ao turismo, ao mercado imobiliário e ao agronegócio. Por outro lado, a indústria continua como mola mestra, impulsionando os setores primário e o terciário. Mesmo saindo da era do capital industrial e diante da crescente valorização do capital na esfera financeira, como dissemos, a autonomia do setor financeiro é relativa, em decorrência das inter-relações do capital financeiro na esfera produtiva.

\section{BIBLIOGRAFIA}

ALVES, Giovanni. Trabalho e Mundialização do Capital. Londrina: Práxis, 1999. . O Novo (e precário) Mundo do Trabalho. São Paulo: Boitempo, 2000. . Dimensões da globalização: o capital e suas contradições. Londrina: Práxis, 2001.

ANTUNES, R. Adeus ao Trabalho? $4^{a}$ edição. São Paulo: Cortez; Campinas, SP: Editora da Universidade Estadual de Campinas, 1997.

BENKO, Georges. Economia espaço e globalização na aurora do século XXI. São Paulo: Hucitec, 1999.

CORRÊA, Roberto Lobato. Região e Organização espacial. São Paulo: Ática, 1995.

CHESNAIS, François. A mundialização do capital. São Paulo: Xamã, 1996.

DRUCK, Maria da Graça. Terceirização (des) Fordizando a Fábrica. Salvador - BA, Edufa, 1995. 
GOMES, Maria Terezinha Serafim. O Debate sobre a Reestruturação Produtiva no Brasil. RA'EGA (2011), p.51-57. Curitiba, Departamento de Geografia - UFPR.

GOTTDIENER, Mark. A produção social do espaço urbano. São Paulo: EDUSP, 1993.

HARVEY, David. A Produção capitalista do espaço. Tradução de Carlos Szlak. São Paulo: Annablume, 2005(Coleção Geografia e Adjacências).

. Condição pós-moderna. São Paulo: Loyola, 1993.

IANNI, Octávio. A era do globalismo. $3^{\mathrm{a}}$ ed. Rio de Janeiro: Civilização Brasileira, 1997.

LENCIONI, Sandra. Condições gerais de produção: um conceito a ser recuperado para a compreensão das desigualdades de desenvolvimento regional. Scripta Nova. Revista electrónica de Geografía y Ciencias Sociales. Barcelona: Universidad de Barcelona, 1 de agosto de 2007, vol. XI, núm. 245 (07). Disponível em: <http://www.ub.es/geocrit/sn/sn-24507.htm> [ISSN: 1138-9788]

. Regiões metropolitanas do Brasil. Radiografia da dinâmica recente do emprego industrial e da remuneração do trabalhador. En publicación: América Latina: cidade, campo y turismo. Amalia Inés Geraiges de Lemos, Mónica Arroyo, María Laura Silveira. CLACSO, Consejo Latinoamericano de Ciencias Sociales, San Pablo. Diciembre 2006. ISBN 978-987-1183-64-7 Disponible en la World Wide Web: http://bibliotecavirtual.clacso.org.ar/ar/libros/edicion/ lemos/06lenci.pdf

. Reconhecendo metrópoles: território e sociedade. In: Metrópole: governo, sociedade e território. SILVA, Catia Antonia da, FREIRE, Désirée Guichard, OLIVEIRA, Floriano José Godinho de (orgs.). - Rio de Janeiro: DP\&A: Faperj, 2006.

. Reestruturação: uma noção fundamental para os estudos transformações e dinâmicas metropolitanas. In: Encontro De Geógrafos da América Latina. VI, Buenos Aires, Universidade de Buenos Aires, 1998b, p.1-10.

MANZAGOL, Claude. Lógica do Espaço Industrial. São Paulo: DIFEL, 1985.

MUNIZ, Alexsandra M. Vieira. A dinâmica da indústria têxtil no espaço metropolitano de Fortaleza. Fortaleza: 2014 (tese de doutorado).

REGO, José Márcio; MARQUES, Rosa Maria (org). Economia Brasileira. 3. ed. São Paulo: Saraiva, 2006.

SPOSITO, Eliseu Savério. O novo mapa da indústria no início do século XXI. 1.ed. São Paulo: Editora da Unesp Digital, 2015.

SANTOS, Milton. Metamorfose do espaço habitado. São Paulo: Hucitec, 1988.

. Técnica, espaço, tempo. Globalização e meio técnico-científico-informacional. São Paulo: Hucitec, 1994.

. Por uma economia política da cidade: o caso de São Paulo. São Paulo: HUCITEC, 1994.

. A natureza do espaço: técnica e tempo. Razão e emoção. São Paulo: Hucitec, 1996; (3ª Ed: 1999; 4ํㅡㄹ edição: 2008).

. Por uma outra globalização: do pensamento único à consciência universal. Rio de Janeiro: Record, 2000.

. SILVEIRA, Maria Laura. O Brasil: território e sociedade no início do século XXI. $9^{\mathrm{a}} \mathrm{ed}$. Rio de Janeiro: Record, 2001.

SENE, Eustáquio de. Globalização e Espaço geográfico. São Paulo: Contexto, 2004. 
SINGER, Paul. Globalização e desemprego: Diagnóstico e alternativas. São Paulo: Contexto, 1998.

SOJA, Edward W. Soja. Geografias Pós-Modernas: A reafirmação do espaço na teoria social crítica. Rio de Janeiro: Zahar, 1993.

\section{NOTAS}

1. É uma tecnologia japonesa que nasceu na Toyota. Permite a administração do estoque com fluxo contínuo de produtos. Segundo Antunes (1997, p.180), Kaban é um sistema de "placas ou senhas de comando para reposição de peças e de estoque que, no toyotismo, devem ser mínimos". Em outras palavras, "o kanban é a senha utilizada que alude à necessidade de reposição das peças/produtos” (ANTUNES, 1997, p.33). É estabelecido um fluxo de informações, que emite especificações acerca da quantidade exata de peças a serem produzidas.

2. Significa produzir no momento exato os produtos necessários na quantidade certa, visando a menores estoques e maior diversidade de produtos.

3. 0 downsizing elimina excesso de burocracia, quando reduz os níveis hierárquicos dentro do processo produtivo.

4. Shumpeter (1946) mostrou a relação entre a inovação tecnológica e os ciclos longos de crescimento econômico, advindos do aumento de investimentos que se seguem à introdução das inovações mais significativas. Ele considerou também diversos aspectos que interagem na inovação, sejam eles técnicos, econômicos, sociais ou gerenciais. A essa dinâmica deu o nome de destruição criativa.

5. O termo regime de acumulação usado por Harvey (1993) reflete a influencia da Escola de Regulação Francesa, ou teoria da regulação concebida em meados do anos de 1970. Para saber mais a este respeito e da crise do regime de acumulação fordista, ver:Michel Aglietta, André Orléan, Robert Boyer, Benjamin Coriat, Alain Lipietz, Bernard Billaudot etc.

6. Nos anos 20 do século XIX, Nicolai Kondratieff apresentou sua teoria sobre as curvas de longo prazo do desenvolvimento capitalista onde afirmou que os longos ciclos no sistema capitalista resultam de sólidos investimentos (fase A de expansão) ou de sua Depreciação (fase B de depressão).

Ao examinar a natureza dos longos ciclos, do ponto de vista das modificações nas técnicas de produção, Kondratieff observou que as regularidades do processo ajudavam a estabelecer algumas regras empíricas para o movimento das longas ondas. E dentro desta perspectiva, Kondratieff revelou o papel das modificações nas técnicas nos longos ciclos.

Assim como Kondratieff, Trotsky, que estava trabalhando no problema do desenvolvimento do capitalismo no pós-guerra, também explorou esse assunto, mas foi com o aparecimento do primeiro trabalho de Kondratieff que ele se envolveu mais uma vez com o assunto reafirmando "sua convicção de que, além dos ciclos industriais 'normais', havia períodos mais extensos na história do capitalismo que eram de grande importância para a compreensão do desenvolvimento a longo prazo do modo de produção capitalista.”(MANDEL, 1983:88).

7. Em vez de usar o termo "globalização" e, portanto, de fazer referência à "economia" de modo vago e impreciso, parece então desde já preferível falar em "globalização do capital", sob a forma tanto do capital produtivo aplicado na indústria e nos serviços quanto do capital concentrado que se valoriza conservando a forma dinheiro. Pode-se 
então dar mais um passo, aquele que consiste em falar de "mundialização" em vez de 'globalização'". Acrescenta ainda Chesnais(1995) que: "A mundialização do capital apresenta-se portanto como uma fase específica de um processo muito mais longo de constituição do mercado mundial em primeiro lugar e, depois, de internacionalização do capital, primeiro sob sua forma financeira e, em seguida, sob sua forma de produção no exterior." (FRANÇOIS, Chesnais, 1995: 5-6). FRANÇOIS, Chesnais. A globalização e o curso do capitalismo de fim-de-século. Traduzido do francês por Catherine Marie Mathieu. Economia e Sociedade, Campinas,1-30, dez.1995.

\section{RESUMOS}

Este estudo constitui a análise de uma das dimensões das mudanças implementadas dentro do paradigma de produção flexível, característico da atual fase do capitalismo, qual seja, a de delinear as principais alterações que ocorrem com a reestruturação produtiva industrial. Objetivando analisar o contexto da reestruturação produtiva no Brasil, procurou-se vincular esta análise ao processo maior de reestruturação capitalista, já que as consequências sociais e espaciais da reestruturação produtiva são algumas de suas múltiplas facetas, sendo fundamental considerarmos a instalação de novos instrumentos de trabalho e as mudanças na organização e gestão da produção, bem como o papel do Estado e da política industrial. Assim, explicitamos o conceito de reestruturação, sua caracterização no setor industrial, sua periodização ao longo do desenvolvimento do capitalismo e alguns reflexos na atividade industrial. Esta investigação retratou ainda as recentes transformações que, de uma forma mais geral, dizem respeito ao modo de produção capitalista no processo de mudanças na economia mundial (abertura de mercado, globalização, reestruturação produtiva), o que permitiu compreender a estrutura, especificidade e dinâmica do trabalho industrial, sublinhando as tendências recentes, traçando um cenário da atividade industrial e suas consequências socioespaciais.

This study constitutes the analysis of one of the dimensions of the changes implemented within the flexible production paradigm, characteristic of the current phase of capitalism, that is, of outlining the main changes that occur with industrial production restructuring. Aiming at analyzing the context of productive restructuring in Brazil, we tried to link this analysis to the larger process of capitalist restructuring, since the social and spatial consequences of productive restructuring are some of its many facets, and it is fundamental to consider the installation of new labor instruments and changes in the organization and management of production, as well as the role of the state and industrial policy. Thus, we explain the concept of restructuring, its characterization in the industrial sector, its periodization along the development of capitalism and some reflexes in industrial activity. This research also portrays the recent transformations that, more generally, concern the capitalist mode of production in the process of changes in the world economy (market opening, globalization, productive restructuring), which allowed to understand the structure, specificity and dynamics of industrial work, underlining recent trends, tracing a scenario of industrial activity and its socio-spatial consequences.

Este estudio constituye el análisis de una de las dimensiones de los cambios implementados dentro del paradigma de la producción flexible, característica de la actual fase del capitalismo, o sea, delinear los principales cambios que ocurren con la reestructuración de la producción 
industrial. Con el objetivo de analizar el contexto de reestructuración productiva en Brasil, intentamos vincular ese análisis al proceso más amplio de reestructuración capitalista, ya que las consecuencias sociales y espaciales de la reestructuración productiva son algunas de sus muchas facetas, y es fundamental considerar la instalación de nuevos instrumentos laborales y cambios en la organización y gestión de la producción, así como el papel de la política estatal e industrial. Así, explicamos el concepto de reestructuración, su caracterización en el sector industrial, su periodización a lo largo del desarrollo del capitalismo y algunos reflejos en la actividad industrial. Esta investigación también retrata las recientes transformaciones que, más generalmente, se refieren al modo de producción capitalista en el proceso de cambios en la economía mundial (apertura de mercado, globalización, reestructuración productiva), que permitieron comprender la estructura, especificidad y dinámica del trabajo industrial. , subrayando las tendencias recientes, trazando un escenario de actividad industrial y sus consecuencias socioespaciales.

Cette étude est l'analyse d'une des dimensions des changements mis en œuvre dans le paradigme de production flexible, caractéristique de la phase actuelle du capitalisme, à savoir esquisser les principaux changements qui surviennent avec la restructuration productive industrielle. Afin d'analyser le contexte de la restructuration productive au Brésil, nous avons cherché à relier cette analyse au processus plus large de la restructuration capitaliste, car les conséquences sociales et spatiales de la restructuration productive sont quelques-unes de ses nombreuses facettes, et il est essentiel d'envisager l'installation de nouveaux outils de travail. et les changements dans l'organisation et la gestion de la production, ainsi que le rôle de l'État et de la politique industrielle. Ainsi, nous expliquons le concept de restructuration, sa caractérisation dans le secteur industriel, sa périodisation tout au long du développement du capitalisme et quelques réflexes sur l'activité industrielle. Cette recherche a également dépeint les transformations récentes qui, plus généralement, concernent le mode de production capitaliste dans le processus de mutation de l'économie mondiale (ouverture des marchés, mondialisation, restructuration productive), ce qui nous a permis de comprendre la structure, la spécificité et la dynamique. travaux industriels, soulignant les tendances récentes, esquissant un scénario d'activité industrielle et ses conséquences socio-spatiales.

\section{ÍNDICE}

Mots-clés: Restructuration productive et spatiale; Géographie; Dynamique industrielle

Keywords: Productive and Spatial Restructuring; Geography; Industrial Dynamics

Palabras claves: Reestructuración Productiva y Espacial; geografía; Dinámica Industrial

Palavras-chave: Reestruturação Produtiva e Espacial; Geografia; Dinâmica Industrial

\section{AUTOR}

\section{ALEXSANDRA M. VIEIRA MUNIZ}

Profa. Adjunta do Departamento de Geografia da Universidade Federal do Ceará. Email:geoalexsandraufc@gmail.com 